\title{
Potential accessibility scores for hospital care in a province of Japan: GIS-based ecological study of the two-step floating catchment area method and the number of neighborhood hospitals
}

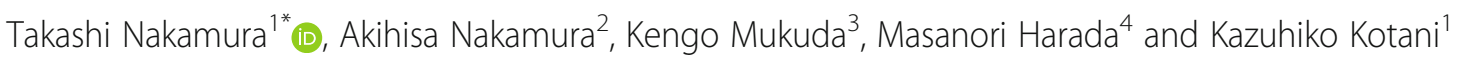

\begin{abstract}
Background: For achieving equity of the accessibility to primary healthcare, measuring potential geographical accessibility is essential. The provider-to-population ratio is the most frequently used measure. However, it is difficult to be used in closer region because it does not take into consideration the people and health services beyond its boundary. In order to overcome this problem, we measured the potential access to hospital, using both distance measures and the enhanced two-step floating catchment area (E2SFCA) method. The aim of this study was to compare the number of hospitals in the neighborhood and the E2SFCA score with regard to the amount and equity for access to hospitals.
\end{abstract}

Methods: This descriptive study used publicly available data from 2010. The E2SFCA score and number of neighborhood hospitals were obtained from Tochigi province in Japan using a geographic information system. Dataset of four measures by each census tract was obtained. The measures were E2SFCA score, number of hospitals within the $5 \mathrm{~km}$ range, number of hospitals within the $10 \mathrm{~km}$ range, and number of hospitals within the $15 \mathrm{~km}$ range. Correlation and disparity analyses with the Lorenz curve and Gini coefficient were performed.

Results: The measures were obtained in a smaller area than municipality considering adjacent areas using a geographical approach. The E2SFCA score was 5.3 [3.2-7.3] hospitals/million (median [quantile range]), compared to 5.6 hospitals/ million in total for the given district. The median number of hospitals within the $5 \mathrm{~km}, 10 \mathrm{~km}$, and $15 \mathrm{~km}$ ranges were 1 , 39 , and 47 , respectively. There was no hospital within the $5 \mathrm{~km}$ range in one third of the blocks. Both the number of hospitals within the $10 \mathrm{~km}$ range and those within the $15 \mathrm{~km}$ range were well correlated. Regional difference became smaller as the distance to count the number of hospitals increased. The gap between small number of hospitals and the high E2SFCA score indicated the location of community hospital in depopulated areas.

Conclusions: The E2SFCA method is superior for analyzing spatial access to hospital, because it provides information in the closer sub-regions. Regional differences were hardly seen in access to hospital beyond the $10 \mathrm{~km}$ range. Further studies in other regions and countries are needed for precise assessment.

Keywords: Potential accessibility, Two-step floating catchment area method, Geographical information system, Distance decay, General practice, Medically underserved area

\footnotetext{
* Correspondence: nakamurata@jichi.ac.jp

${ }^{1}$ Center for Community Medicine, Jichi Medical University, 3311-1 Yakushiji

Shimotsuke, Tochigi 3290498, Japan

Full list of author information is available at the end of the article
} 


\section{Background}

Maximizing and achieving equity of access to primary healthcare are prerequisites for achieving health. The vast majority of aged population was within close proximity to hospital facilities in Illinois, US [1]. However, inaccessibility of hospital services may increase the risk of asthma mortality [2] and overuse of cesarean delivery [3]. Accessibility to hospital care is one of the determinants of health.

"Access to healthcare" is often mentioned. However, there are complexities in the concept of access to primary healthcare [4]. The determination of "access to healthcare" remains unclear. Penchansky and Thomas mentioned five dimensions of access, including availability, accessibility, accommodation, affordability, and acceptability [5]. In this study, we focused on the spatial [6] or geographical profile of potential accessibility. Potential accessibility does not account for the realized utilization of medical care [7]. In the context of the medically underserved, whether healthcare is present at a site is important, as well as its utilization.

Measurements of the geographical profile of potential accessibility have some variations. Distance and travel time measures are two of the simplest ways of measuring potential access. Density measures including Kernel estimates of service density, two-step floating catchment area method are also known [8]. The two-step floating catchment area (2SFCA) method has been proposed as an example of a catchment model [9]. Thus, both distance measures and 2SFCA method have been employed in this study.

Recent literature concerned with the metrics of access to healthcare has focused on 2SFCA approaches, which are essentially a specialized form of the gravity model [10]. The 2SFCA method uses point features to represent the location of services and demand. In the first step, a distance catchment is placed around each primary healthcare service provider and a provider-to-population ratio is computed using the number of providers and estimated population falling within the area. In the second step, a similar floating catchment is placed over each demand center and the service accessibility for this population is rated by summing all provider-to-population ratios contained within the zone.

For the earliest version of the 2SFCA model, there are many criticisms, such as its reliance on a finite catchment size [11]. To address the concerns, an enhanced two-step floating catchment area (E2SFCA) method was proposed involving the introduction of a distance decay function into the floating catchments of both algorithmic steps [12]. The E2SFCA method is available for measuring spatial accessibility to primary care physicians $[12,13]$. An increasing number of reports on geographical accessibility to primary healthcare are available from different countries, including China [14, 15], US [16, 17], Canada [18], Australia [19-21], India [22], Japan [23], and some other countries. Harada et al. showed the equity of accessibility using the Lorenz curve and Gini coefficient of the number of hospitals within certain ranges [24].

The aim of this study was to compare the E2SFCA score and the number of neighborhood hospitals with regard to both amount and equity.

\section{Methods \\ Design}

The present study is a descriptive study using a geographical information system with publicly available data from 2010.

\section{Subject area}

The administrative census mesh block ("Cho-cho-aza") in Tochigi province in Japan was set as the subject area. The population was 2,007,683, with 110 hospitals in 2010. The total number of hospital per 100,000 was 5.5 .

\section{Data source}

Population and the location of each block were extracted from ArcGIS data collection standard pack 2015 (Esri Japan Corporation, Tokyo, Japan). This database included data from Census 2010. The location of hospitals in 2010 was extracted from the National Land Numerical Information download service of the Land, Infrastructure and Transportation Ministry. The road network data in 2010 was extracted from the ArcGIS data collection road network, which included data from the Road Traffic Census 2010.

\section{Distance from each block to each hospital}

Every subject block was included, and every hospital in both Tochigi province and the neighboring provinces was included. Therefore, we accounted for the neighboring population beyond the border of Tochigi province. The distance from each block to each hospital was calculated using the Origin-Destination Cost Matrix command of ArcMap 10.4.1 (Esri, Redlands, CA, USA), and data, including the location of each block, location of each hospital, and road network information, were used. Thus, the distance data matrix of each block according to the hospital was obtained.

\section{Distance measures: Number of neighborhood hospitals}

According to the distance between a block and hospital, the number of hospitals within the $5 \mathrm{~km}$ range from each block was determined. The number of hospitals within the $10 \mathrm{~km}$ range and the number of hospitals within the $15 \mathrm{~km}$ range were similarly calculated. The majority of the aged are within a $7.7 \mathrm{~km}$ range of a hospital and an 
Table 1 Population, the number of neighborhood hospitals, and the E2SFCA score

\begin{tabular}{llll}
\hline & $\mathrm{N}$ & Median & (Quantile range) \\
\hline Population & 2583 & 456 & $(199-879)$ \\
Area $\left(\mathrm{km}^{2}\right)$ & 2583 & 0.60 & $(0.14-2.27)$ \\
$\begin{array}{l}\text { Number of hospitals within } \\
\text { the } 5 \mathrm{~km} \text { range }\end{array}$ & 2583 & 1 & $(0-4)$ \\
$\begin{array}{l}\text { Number of hospitals within } \\
\text { the } 10 \mathrm{~km} \text { range }\end{array}$ & 2583 & 39 & $(32-51)$ \\
$\begin{array}{l}\text { Number of hospitals within } \\
\text { the } 15 \mathrm{~km} \text { range }\end{array}$ & 2583 & 47 & $(38-58)$ \\
\begin{tabular}{l} 
E2SFCA score \\
\hline
\end{tabular} & 2583 & 5.3 & $(3.2-7.3)$ \\
\hline
\end{tabular}

$18.6 \mathrm{~km}$ range of two hospitals in Illinois [1]. The distance decay function from the $5 \mathrm{~km}$ to $15 \mathrm{~km}$ distance was used to generate rural primary care access [20]. Therefore, $5 \mathrm{~km}, 10 \mathrm{~km}$, and $15 \mathrm{~km}$ ranges were set for this measure.

\section{E2SFCA method}

According to the distance between a block and hospital, the weighing coefficient of distance decay was assessed (Eq. 1). The number of hospitals within the $5 \mathrm{~km}$ range was weighed as 1 , the number of hospitals beyond the $15 \mathrm{~km}$ range was weighed as 0 , and the number of hospitals between the $5 \mathrm{~km}$ and $15 \mathrm{~km}$ ranges was weighed as a coefficient with distance decay [20].

Equation 1 Weighing coefficient formula according to distance

$$
W_{i, j}=\left\{\begin{array}{cr}
1 & d_{i, j}<5 \\
\left(\frac{15-d_{i, j}}{15-5}\right)^{1.5} & , 5 \leq d_{i, j} \leq 10 \\
0 & , 10 \leq d_{i, j}
\end{array}\right.
$$

where $d_{i, j}$ represents the distance $[\mathrm{km}]$ between block $i$ and hospital $j$.

In the first step, the catchment population of each hospital was calculated. The population in each block was weighed by distance decay, and the sum of the population according to each hospital was obtained (Eq. 2).

Equation 2 Step 1: Catchment population around each hospital

$$
P_{j}=\sum_{i} W_{i, j} \times P_{i}
$$

where $P_{j}$ represents the neighborhood population around hospital $j, W_{i, j}$ represents the weighing coefficient, and $P_{i}$ represents the population within block $i$.

In the second step, the providers to the catchment population in each block were calculated. The reciprocal of the catchment population of each hospital was weighed by the distance decay, and the sum of its ratio according to each block was the E2SFCA score (Eq. 3).

Equation 3 Step 2: E2SFCA score

$$
E 2 S F C A_{i}=\sum_{j} \frac{W_{i, j} \times S_{j}}{P_{j}}
$$

where $E 2 S F C A_{i}$ represents the E2SFCA score of block $i$, $P_{j}$ represents the neighborhood population around hospital $j, W_{i, j}$ represents the weighing coefficient, and $S_{j}$ represents the number of providers in hospital $j$. With regard to the number of hospitals, $S_{j}=1$.

\section{Statistical analysis}

The dataset of four measures according to each census tract was obtained with the procedure above. The measures were the number of hospitals within the $5 \mathrm{~km}$ range, number of hospitals within the $10 \mathrm{~km}$ range, number of hospitals within the $15 \mathrm{~km}$ range, and E2SFCA score. To investigate the relationship among the four measures, we performed correlation analysis using Spearman's rank-order correlation. Then, to investigate disparity among the four measures, we performed disparity analysis using the Lorenz curve and the Gini coefficient. The Gini coefficient ranges from 0 to 1 . The Gini coefficient 0 represents no disparity, and the Gini coefficient 1 represents maximum disparity. Stata/SE 14.2 (StataCorp, College Station, TX, US) was used for all statistical analyses. The alpha error was set to 0.05 for significance.

\section{Results}

\section{Characteristics of the measures}

There were 2583 census blocks, including 46 blocks with no residents. The median population of each block was 456 , and the median area was $0.60 \mathrm{~km}^{2}$. The numbers of hospitals within the $5 \mathrm{~km}, 10 \mathrm{~km}$, and $15 \mathrm{~km}$ ranges were 1,39 , and 47 , respectively. The number of blocks

Table 2 Spearman's correlation analysis

\begin{tabular}{lllll}
\hline & Population & $5 \mathrm{~km}$ & $10 \mathrm{~km}$ & $15 \mathrm{~km}$ \\
\hline $5 \mathrm{~km}$ & $-0.266(p<0.01)$ & & & \\
$10 \mathrm{~km}$ & $-0.112(p<0.01)$ & $0.142(p<0.01)$ & $0.898(p<0.01)$ & $0.344(p<0.01)$ \\
$15 \mathrm{~km}$ & -0.002 (n.s.) & $0.225(p<0.01)$ & $0.278(p<0.01)$ \\
E2SFCA & $0.066(p<0.01)$ & $0.696(p<0.01)$ & $0.344)$ \\
\hline
\end{tabular}




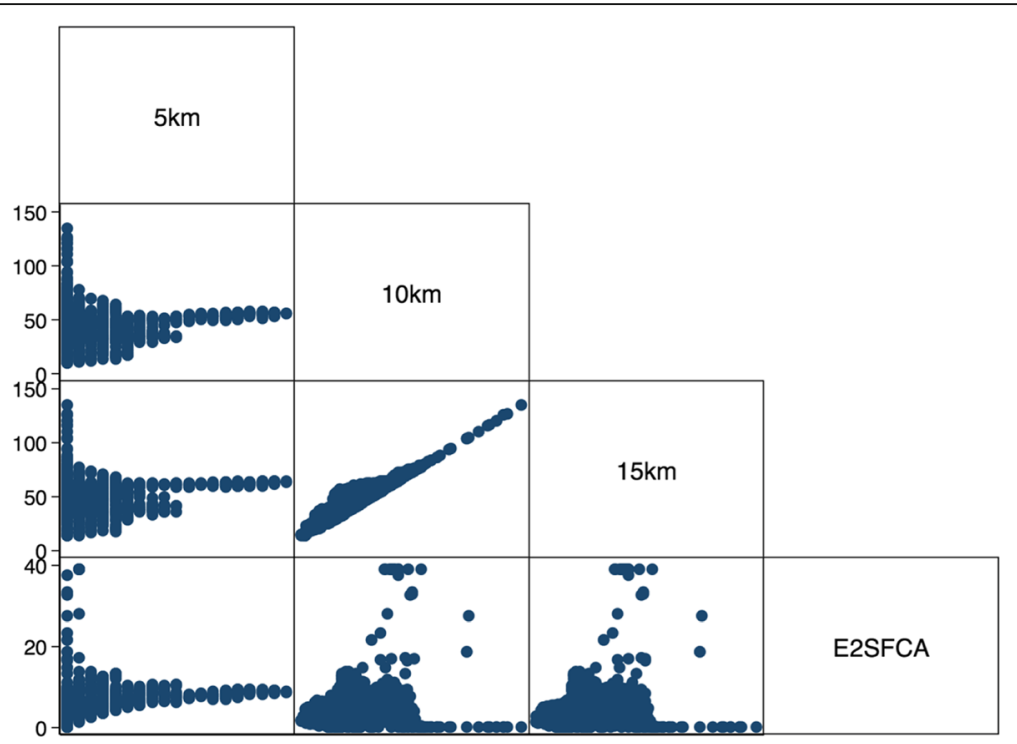

Fig. 1 Scatter plot of the number of neighborhood hospitals and the E2SFCA score. Footnote: $5 \mathrm{~km}$, number of hospitals within the $5 \mathrm{~km}$ range; $10 \mathrm{~km}$, number of hospitals within the $10 \mathrm{~km}$ range; $15 \mathrm{~km}$, number of hospitals within the $15 \mathrm{~km}$ range; E2SFCA, E2SFCA score

where there was no hospital within the $5 \mathrm{~km}$ range was 825 (32.0\%). There were at least 9 hospitals within the $10 \mathrm{~km}$ range. Total number of hospitals per 100,000 people (5.6) and the E2SFCA (5.3 [3.2-7.3], median [quantile range]) were almost the same (Table 1).

\section{Correlation among the measures}

Correlation analyses among the different variables were performed. A significant correlation was noted between the E2SFCA score and the number of hospitals within the $5 \mathrm{~km}$ range (Spearman's $\rho=0.696$, $p<0.01$ ) (Table 2), although a scatter plot showed limited tendency (Fig. 1). It suggests that each measurement reflects another aspect of the potential accessibility to hospital. Additionally, a significant positive correlation was noted between the number of hospitals within the $10 \mathrm{~km}$ range and the number of hospitals within the $15 \mathrm{~km}$ range (Spearman's $\rho=0.898, p<0.01$ ) with linear correlation in the scatter plot (Fig. 1). It suggests that both the number of hospitals within the $10 \mathrm{~km}$ range and those within the $15 \mathrm{~km}$ range reflected similar aspect of the potential accessibility to hospital.

Multi-comparisons were corrected with Bonferroni correction. Footnote: n.s., $p>0.05 ; 5 \mathrm{~km}$, the number of hospitals within the $5 \mathrm{~km}$ range; $10 \mathrm{~km}$, the number of hospitals within the $10 \mathrm{~km}$ range; $15 \mathrm{~km}$, the number of hospitals within the $15 \mathrm{~km}$ range; E2SFCA, E2SFCA score.

\section{Disparity among the measures}

The Gini coefficient of each variable was calculated. The Gini coefficient became smaller as the distance for counting the number of hospitals increased. The
Gini coefficient of E2SFCA score and Lorenz curve were within the range between the coefficient of the number of hospitals within the $5 \mathrm{~km}$ range and that of the number of hospitals within the $10 \mathrm{~km}$ range (Table 3, Fig. 2).

\section{Geographical distribution}

The geographical distribution maps of the population, locations of hospitals, number of hospitals within $5 \mathrm{~km}$, and E2SFCA score are presented in Fig. 3. In the central and the south region, there were many hospitals and the E2SFCA score was high. In the north region, the E2SFCA score was high, though the number of hospitals was small. This was because there were community hospitals in depopulated regions.

\section{Discussion}

In this study, we compared access to hospital in a province of Japan with two measures, i.e. E2SFCA score and the number of hospitals within certain distance ranges. With conventional measures such as the number of hospitals per the number of people in the region, it was difficult to use in smaller area units than municipalities.

Table 3 The Gini coefficients from the Lorenz curve

\begin{tabular}{ll}
\hline & The Gini Coef \\
\hline Number of hospitals within the $5 \mathrm{~km}$ range & 0.645 \\
Number of hospitals within the $10 \mathrm{~km}$ range & 0.175 \\
Number of hospitals within the $15 \mathrm{~km}$ range & 0.150 \\
E2SFCA score & 0.348 \\
\hline
\end{tabular}




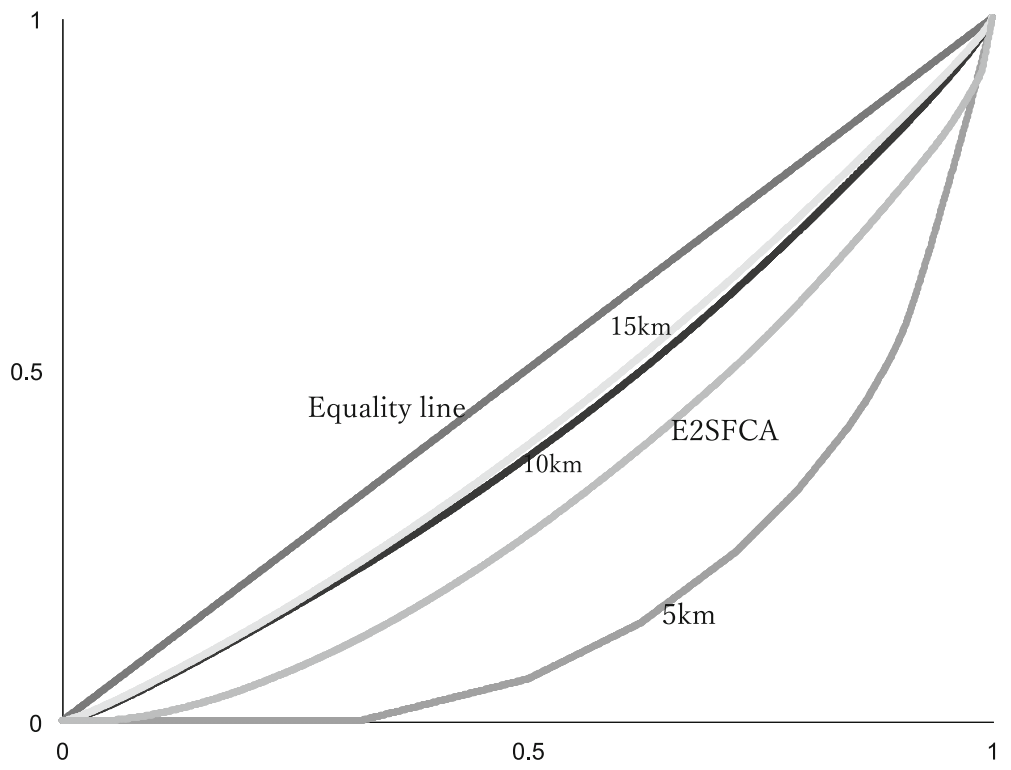

Fig. 2 Lorenz curve of the regional distribution of the accessibility scores. The percentage of regional blocks is plotted on the $x$-axis, and the percentage of the accessibility scores in plotted on the $y$-axis. The diagonal line is the line of equality. A greater distance from the line of equality indicates a higher disparity in the regional distribution of the accessibility scores. Footnote: $5 \mathrm{~km}$, number of hospitals within the $5 \mathrm{~km}$ range; $10 \mathrm{~km}$, number of hospitals within the $10 \mathrm{~km}$ range; $15 \mathrm{~km}$, number of hospitals within the $15 \mathrm{~km}$ range; E2SFCA, E2SFCA score

The number of hospitals per population in the target district approximated the average of E2SFCA scores calculated for each sub-region (5.3 hospitals/million persons). There were different characteristics between E2SFCA score and the number of hospitals within certain distances. There were no hospitals within the $5 \mathrm{~km}$ range in one third of the blocks. There was a strong correlation between the number of hospitals within the $10 \mathrm{~km}$ range and the number of hospitals within the $15 \mathrm{~km}$ range.

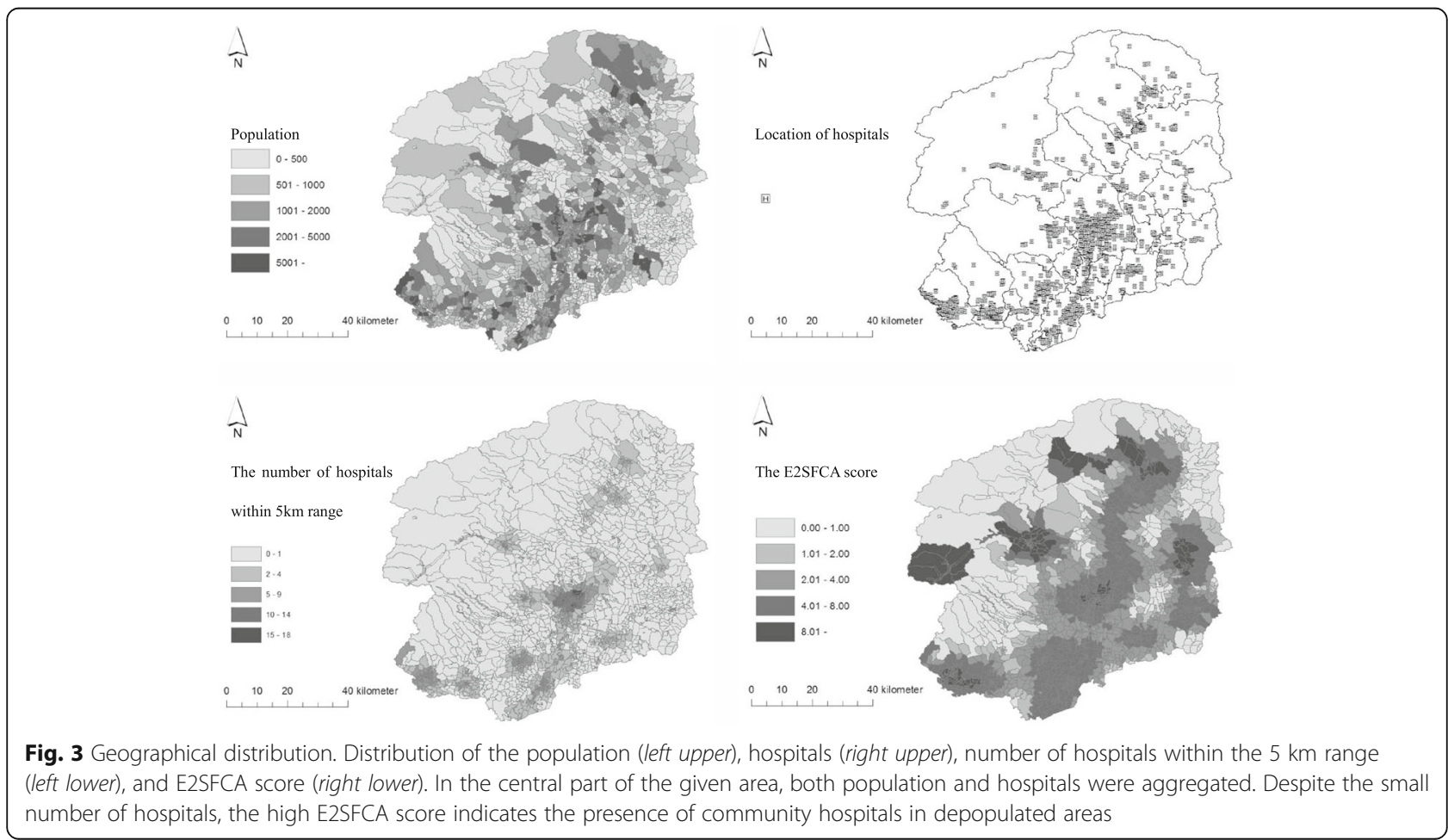


The number of hospitals within certain distance ranges may reflect healthcare opportunities for each resident. The number of hospitals increases as the distance range increases, but there was little difference between the number of hospitals within the $10 \mathrm{~km}$ range and the number of hospitals within the $15 \mathrm{~km}$ range. Although the Japanese law limits the number of beds for each medical district consisting of one or more municipalities, the location of the hospital follows an economic principle. Aoki et al. showed that the appropriate area was within the $15-20 \mathrm{~km}$ range from the hospital in an ecological study of the number of patients seeking hospitals [25]. The regional distance of seeking hospitals among Japanese people might be around $10 \mathrm{~km}$.

E2SFCA score reflects the balance between the number of hospitals and the population. One of the simplest measures for this balance is the number of hospitals per the number of people in the region, within a certain range. However, this conventional measure does not take into consideration the population or hospitals outside the boundary; it does not work well in the setting of narrower regional units. E2SFCA method made it possible to evaluate access to healthcare in narrower area unit by considering neighborhood areas. Furthermore, since the score approximates to the conventional indicator, it is easy to understand intuitively. It would be used to evaluate the localization of the poorer accessibility to hospital care.

The present study has some limitations. Spatial potential accessibility to hospital care was assessed in the current study. The catchment area in the real world differs from hospital to hospital [21, 26]. Additionally, the traffic situation may affect accessibility [27]. A number of variation of the 2SFCA method have been devised, including the optimized 2SFCA method with accounting for the number of realized visiting patients [18], commuter-based version of the 2SFCA method [28], three-step floating catchment area method [29], modified 2SFCA method [30, 31], enhanced variable two-step floating catchment area (EV2SFCA) method [32], and multi-criterion two-step floating catchment area method [33]. Another formula of the distance decay used in this study has been proposed [11]. Furthermore, this study was performed in a certain district of Japan. As mention above, the accessibility to healthcare could be affected by county-specific social background factors, including traffic conditions and the healthcare system. Further studies in other regions and other countries are needed for precise assessment.

\section{Conclusions}

The E2SFCA method is superior for analyzing spatial access to hospital, because it would provide information in the closer sub-regions with the approximate value and the same unit dimension as conventional providerto-population ratio measure. Regional differences were hardly seen in access to hospital beyond the $10 \mathrm{~km}$ range.

\section{Abbreviations \\ 2SFCA: Two-step floating catchment area; E2SFCA: Enhanced two-step float- ing catchment area \\ Acknowledgments \\ The authors would like to thank Enago (https:/www.enago.jp) for the English language review and the journal reviewers for enhancing the quality of the manuscript.}

\section{Funding}

This work was supported by JSPS Grant-in-Aid Scientific Research(C) No.16 K09140

\section{Availability of data and materials}

The datasets used and analyzed during the current study are available from the corresponding author on reasonable request.

\section{Authors' contributions}

TN conducted the GIS-based ecological study, performed the analysis, wrote the draft of the manuscript, and wrote the final version of the manuscript. $\mathrm{KK}$ participated in the design. $\mathrm{AN}, \mathrm{KM}, \mathrm{MH}$, and $\mathrm{KK}$ participated in helping to draft the manuscript. All authors read and approved the final manuscript.

\section{Authors' information}

Not applicable.

\section{Competing interests}

The authors declare that they have no competing interests.

Consent for publication

Not applicable.

Ethics approval and consent to participate

Not applicable.

\section{Publisher's Note}

Springer Nature remains neutral with regard to jurisdictional claims in published maps and institutional affiliations.

\section{Author details}

${ }^{1}$ Center for Community Medicine, Jichi Medical University, 3311-1 Yakushiji Shimotsuke, Tochigi 3290498, Japan. ${ }^{2}$ Gero Municipal Osaka Clinic, 1965 Ohshima Osaka Gero, Gifu 5093106, Japan. ${ }^{3}$ Internal Medicine, Nichinan Hospital, 511-7 Shoyama Nichinan Hino, Tottori 6895211, Japan. ${ }^{4}$ Department for Support of Rural Medicine, Yamaguchi Grand Medical Center, 77 Ohsaki Hofu, Yamaguchi 7478511, Japan.

Received: 12 January 2017 Accepted: 8 June 2017

Published online: 26 June 2017

\section{References}

1. Love $D$, Lidquist $P$. The geographical accessibility of hospitals to the aged: a geographic information systems analysis within Illinois. Health Serv Res. 1995;29:629.

2. Jones AP, Bentham G, Horwell C. Health service accessibility and deaths from asthma. Int J Epidemiol. 1999;28:101.

3. Freitas PF, Drachler MdeL, Leite JC, et al. Inequalities in cesarean delivery rates by ethnicity and hospital accessibility in Brazil. Int J Gynaecol Obstet. 2009;107:198.

4. Ansari Z. A review of literature on access to primary health care. Aust J Prim Health 2007;13:80-95.

5. Penchansky R, Thomas JW. The concept of access: definition and relationship to consumer satisfaction. Med Care. 1981;19:127-40. 
6. Khan AA, Bhardwaj SM. Access to health care. A conceptual framework and its relevance to health care planning. Eval Health Prof. 1994;17:60-76.

7. Guagliardo MF. Spatial accessibility of primary care: concepts, methods and challenges. Int J Health Geogr. 2004;3:3.

8. Cromley EK, McLafferty SL. GIS and public health 2nd edition. New York: The Guilford Press; 2012. p. 303-37.

9. Allan DP. Catchments of general practice in different countries- a literature review. Int J Health Geogr. 2014;13:32.

10. Luo W, Wang F. Measures of spatial accessibility to health care in a GIS environment: synthesis and a case study in the Chicago region. Environ Plann B. 2003;30:865-84.

11. Wang F. Measurement, optimization, and impact of health care accessibility: a methodological review. Ann Assoc Am Geogr. 2012;102:1104-12.

12. Luo W, Qi Y. An enhanced two-step floating catchment area (E2SFCA) method for measuring spatial accessibility to primary care physicians. Health Place. 2009;15:1100-7.

13. McGrail MR. Spatial accessibility of primary health care utilising the two step floating catchment area method: an assessment of recent improvements. Int J Health Geogr. 2012;11:50.

14. Cheng Y, Wang J, Rosenberg MW. Spatial access to residential care resources in Beijing. China Int J Health Geogr. 2012;11:32.

15. Hu R, Dong S, Zhao Y, Hu H, Li Z. Assessing potential spatial accessibility of health services in rural China: a case study of Donghai county. Int J Equity Health. 2013;12:35.

16. Luo W. Using a GIS-based floating catchment method to assess areas with shortage of physicians. Health Place. 2004;10:1-11.

17. McLafferty S, Wang F. Rural reversal? Cancer. 2009;115:2755-64.

18. Ngui AN, Apparicio P. Optimizing the two-step floating catchment area method for measuring spatial accessibility to medical clinics in Montreal. BMC Health Serv Res. 2011;11:166.

19. Scott J, Larson A, Jefferies F, Veenendaal B. Small-area estimates of general practice workforce shortage in rural and remote Western Australia. Aust J Rural Health. 2006;14:209-13.

20. McGrail MR, Humphreys JS. The index of rural access: an innovative integrated approach for measuring primary care access. BMC Health Serv Res. 2009;9:124.

21. McGrail MR, Humphreys JS. Measuring spatial accessibility to primary care in rural areas: improving the effectiveness of the two-step floating catchment area method. Appl Geogr. 2009;29:533-41.

22. Vadrevu L, Kanjilal B. Measuring spatial equity and access to maternal health services using enhanced two step floating catchment area method (E2SFCA) a case study of the Indian Sundarbans. Int J Equity Health. 2016;15:87.

23. Cervigni F, Suzuki $Y$, Ishii T, Hata A. Spatial accessibility to pediatric services. J Community Health. 2008;33:444-8.

24. Harada M, Okayama M, Ae R, Kojo T, Aihara M, Kajii E. A study on regional disparities in access to inpatient care, using the Gini coefficient. Gen Med. 2012;13:25-9.

25. Aoki M, Tomokiyo T. A study on the medical service area and the utility circle of the practitioner in the joint use type hospital. Trans Architectural Inst Jpn. 1983:332:111-7.

26. Luo W, Whippo T. Variable catchment sizes for the two-step floating catchment area (2SFCA) method. Health Place. 2012;18:789-95.

27. Langford M, Higgs G, Fry R. Multi-modal two-step floating catchment area analysis of primary health care accessibility. Health Place. 2016:38:70-81.

28. Fransen $K$, Neutens T, De Maeyer P, Deruyter G. A commuter-based twostep floating catchment area method for measuring spatial accessibility of daycare centers. Health Place. 2015;32:65-73.

29. Wan N, Zou B, Sternberg T. A three-step floating catchment area method for analyzing spatial access to health services. Int J Geogr Inf Sci. 2012;26:1073-89.

30. Langford M, Fry R, Higgs $G$. Measuring transit system accessibility using a modified two-step floating catchment technique. Int J Geogr Inf Sci. 2012; 26:193-214.

31. Delamater PL. Spatial accessibility in suboptimally configured health care systems: a modified two-step floating catchment area (M2SFCA) metric. Health Place. 2013;24:30-43.

32. Ni J, Wang J, Rui Y, Qian T, Wang J. An enhanced variable two-step floating catchment area method for measuring spatial accessibility to residential care facilities in Nanjing. Int J Environ Res Public Health. 2015;12:14490-504.

33. Lin BC, Chen CW, Chen CC, Kuo CL, Fan IC, Ho CK, et al. Spatial decision on allocating automated external defibrillators (AED) in communities by multicriterion two-step floating catchment area (MC2SFCA). Int J Health Geogr. 2016;15:17.

\section{Submit your next manuscript to BioMed Central and we will help you at every step:}

- We accept pre-submission inquiries

- Our selector tool helps you to find the most relevant journal

- We provide round the clock customer support

- Convenient online submission

- Thorough peer review

- Inclusion in PubMed and all major indexing services

- Maximum visibility for your research

Submit your manuscript at www.biomedcentral.com/submit
Biomed Central 